\title{
Optimum Dispersion Parameters of Carbon Nanotubes: Concrete Strength by Response Surface Methodologies
}

\author{
Mohamed Mohsen \\ 200202128@qu.edu.qa \\ Department of Civil and Architectural Engineering, Qatar University, Doha, Qatar \\ Mohamed Al Ansari \\ m.alansari@qu.edu.qa \\ Department of Civil and Architectural Engineering, Qatar University, Doha, Qatar \\ Ramzi Taha \\ ramzitaha@gmail.com \\ College of Engineering, Phoenicia University, Beirut, Lebanon
}

\author{
Ahmed Senouci \\ asenouci@central.uh.edu \\ Department of Construction Management, University of Houston, Houston, Texas, USA
}

\author{
Ala AbuTaqa \\ aa1104819@qu.edu.qa
}

Department of Civil and Architectural Engineering, Qatar University, Doha, Qatar

\begin{abstract}
This paper implements Response Surface Methodologies (RSM) techniques to illustrate the maximum carbon nanotubes (CNTs)-concrete mechanical properties responses to the length, weight fraction and treatment variables. Mixes with different CNTs' content were prepared and tested for flexure, compression and tension. RSM analysis showed that the highest effect on the strengths was due to the CNTs' content variable. The analysis showed that a weight fraction of $0.3 \mathrm{wt} . \%$ of non-treated CNTs is required to achieve the maximum flexural, compressive and tensile strengths in a batch as per the predicted model. RSM analysis also showed that maximum flexural strength will be obtained by using 0.2 wt. $\%$ non-treated long CNTs, 0.25 wt. \% non-treated short CNTs and 0.03 wt. $\%$ treated long CNTs, respectively.
\end{abstract}

Keywords: Carbon nanotubes; CNTs' dispersion; Concrete strength; Response surface Methodologies

\section{INTRODUCTION}

In the last decade, carbon nanotubes (CNTs) were extensively integrated into cementitious materials studies. Researchers investigated the effect of CNTs' addition on the mechanical, physical, chemical, rheological and microstructural properties of cement pastes and mortars. The major challenge in most studies was about providing an acceptable CNTs' dispersion within the water solution and eventually the cementitious matrix. Many variables affecting the dispersion such as CNTs' weight fraction, aspect ratio, functionalization, mixing procedure and surfactant types, surfactants amount and 
sonication energy were investigated (Wang et al., 2013; Chuah et al., 2014; Paula et al., 2014; Siddique et al, 2014; Abu-Taqa et al, 2015; Al-Dahawi et al., 2016; Song et al., 2017; Mohsen et al., 2017; Kramer et al., 2017; Hawreen et al., 2018). Through these studies, the body of knowledge in this field could reach several understandings about the CNTs' amount, CNTs' type and mixing procedures to follow for achieving improvements in the flexural, compressive and tensile strengths of CNT composites. However, up to this moment, a mix design with the optimum length, weight fraction and treatment amount to provide the highest mechanical properties is not observed. In this study, RSM methods are used to investigate the optimum mix proportions to produce the highest flexural, compressive and tensile strength properties. First, CNTs-concrete batches were prepared and tested. Then, Response Surface Methods (RSM) were used to fit a proper model on the collected data.

\section{EXPERIMENTAL DESIGN}

Table 1 summarizes the tested batches. The testing methodology started with the preparation of the batches and specimens, followed by the measurement of their flexural, compressive and tensile strengths. Then, analyzing the test results using RSM techniques.

\subsection{Materials and Equipment}

The cement used in this work was Portland cement, CEM I, Class $42.5 \mathrm{R}$ complying with EN 197-1. It was supplied by Qatar National Cement Company (QNCC). The fine and coarse aggregates supplied by Qatar Primary Materials Company (QPMC) were in accordance with ASTM C-33, Standard Specification for Concrete Aggregates. The CNTs used were multi-walled carbon nanotubes (MWCNTs), supplied by Cheaptubes, Inc., and they were differentiated by lengths and treatment type. The surfactant used to disperse the CNTs is a liquid polymer superplasticizer of a polycarboxylate chain, supplied by Sika Qatar L.L.C. The equipment used in this study comprised of a strength-testing machine, supplied by Controls Inc., an 85 liters site concrete mixer and an ultrasonic wave mixer with a commercial name VCX750, supplied by Sonics \& Materials, Inc., was used for dispersing CNTs into water.

Table 1: Testing Matrix

\begin{tabular}{|c|c|c|c|c|c|}
\hline Batch \# & Batch Name & $\begin{array}{c}\text { CNT/Cement } \\
\text { Content (wt\%) }\end{array}$ & CNTs Treated & CNTs Length $(\boldsymbol{\mu m})$ & $\begin{array}{c}\text { Number of } \\
\text { specimens }\end{array}$ \\
\hline 1 & 0.03 NCNT & 0.03 & No & $10-30$ & 27 \\
\hline 2 & 0.08 NCNT & 0.08 & No & $10-30$ & 27 \\
\hline 3 & 0.25 NCNT & 0.25 & No & $10-30$ & 27 \\
\hline 4 & 0.5 NCNT & 0.5 & No & $10-30$ & 27 \\
\hline 5 & 0.03 TCNT & 0.03 & Yes & $10-30$ & 27 \\
\hline 6 & 0.08 TCNT & 0.08 & Yes & $10-30$ & 27 \\
\hline 7 & 0.25 TCNT & 0.25 & Yes & $10-30$ & 27 \\
\hline 8 & 0.5 TCNT & 0.5 & Yes & $10-30$ & 27 \\
\hline 9 & 0.03 SCNT & 0.03 & No & $0.5-2$ & 27 \\
\hline 10 & 0.08 SCNT & 0.08 & No & $0.5-2$ & 27 \\
\hline 11 & 0.25 SCNT & 0.25 & No & $0.5-2$ & 27 \\
\hline 12 & 0.5 SCNT & 0.5 & No & $0.5-2$ & 27 \\
\hline
\end{tabular}

\subsection{Mixing and Testing}

The mixing procedure was divided into two processes. The first process included the CNTs dispersion in water using an ultrasonicator, while the second part comprised 
of mixing the dispersed solution with cement, coarse and fine aggregate in the concrete mixer. The duration of the whole sonication and mixing procedures was 1 hour. The flexural, compressive and tensile strength testing of concrete-CNTs' samples was conducted according to ASTM C78/C78M-10, ASTM C39/C39M-16 and ASTM C496/ C496M-11 standards, respectively.

\subsection{Response Surface Methods (RSM) Techniques}

The Central Composite Design (CCD) Response Method was used to fit a quadratic model for each phase parameter. This was performed by determining the maximum response of the flexural, compressive and tensile strengths factors using the JMP software. The methodology followed to perform this analysis is as follows:

1- The CNTs' weight fractions, treatment type and length type variables were coded in the $(-1,1)$ interval (Table 2$)$.

2- The factors were modeled by fitting a second order polynomial equation model. Second order polynomial equations were used to express the flexural and compressive strengths as functions of independent variables:

$$
\begin{aligned}
\mathrm{FS}= & \mathrm{a}_{0}+\mathrm{a}_{1} \mathrm{x}_{1}+\mathrm{a}_{2} \mathrm{x}_{2}+\mathrm{a}_{3} \mathrm{x}_{3}+\mathrm{a}_{12} \mathrm{x}_{1} \mathrm{x}_{2}+\mathrm{a}_{13} \mathrm{x}_{1} \mathrm{x}_{3}+\mathrm{a}_{23} \mathrm{x}_{2} \mathrm{x}_{3}+\mathrm{a}_{11} \mathrm{x}_{1}{ }^{2}+\mathrm{a}_{22} \mathrm{x}_{2}{ }^{2}+\mathrm{a}_{33} \mathrm{x}_{3}^{2}[1] \\
\mathrm{CS}= & \mathrm{b}_{0}+\mathrm{b}_{1} \mathrm{x}_{1}+\mathrm{b}_{2} \mathrm{x}_{2}+\mathrm{b}_{3} \mathrm{x}_{3}+\mathrm{b}_{12} \mathrm{x}_{1} \mathrm{x}_{2}+\mathrm{b}_{13} \mathrm{x}_{1} \mathrm{x}_{3}+\mathrm{b}_{23} \mathrm{x}_{2} \mathrm{x}_{3}+\mathrm{b}_{11} \mathrm{x}^{2}+\mathrm{b}_{22} \mathrm{x}^{2}+\mathrm{b}_{33} \mathrm{x}^{2}[2] \\
\mathrm{TS}= & \mathrm{c}_{0}+\mathrm{c}_{1} \mathrm{x}_{1}+\mathrm{c}_{2} \mathrm{x}_{2}+\mathrm{c}_{3} \mathrm{x}_{3}+\mathrm{c}_{12} \mathrm{x}_{1} \mathrm{x}_{2}+\mathrm{c}_{13} \mathrm{x}_{1} \mathrm{x}_{3}+\mathrm{c}_{23} \mathrm{x}_{2} \mathrm{x}_{3}+\mathrm{c}_{11} \mathrm{x}_{1}{ }^{2}+\mathrm{c}_{22} \mathrm{x}_{2}{ }^{2}+\mathrm{c}_{33} \mathrm{x}_{3}^{2}[3] \\
& \text { where: FS = flexural strength (MPa), } \\
& \text { CS }=\text { Compressive strength }(\mathrm{MPa}), \\
& \text { TS }=\text { Tensile strength (MPa), } \\
& \mathrm{x}_{1}=\text { CNTs-concrete weight fraction }(\%), \\
& \mathrm{x}_{2}=\text { CNTs treatment, and } \\
& \mathrm{x}_{3}=\text { CNTs length. } \\
& \mathrm{a}_{0}, \mathrm{a}_{1}, \mathrm{a}_{2}, \mathrm{a} 3, \mathrm{a}_{12}, \mathrm{a}_{13}, \mathrm{a}_{23}, \mathrm{a}_{11}, \mathrm{a}_{22}, \mathrm{a}_{33}, \mathrm{~b}_{0}, \mathrm{~b}_{1}, \mathrm{~b}_{2}, \mathrm{~b}_{3}, \mathrm{~b}_{12}, \mathrm{~b}_{13}, \mathrm{~b}_{23}, \mathrm{~b}_{11}, \mathrm{~b}_{22}, \mathrm{~b}_{33}, \mathrm{c}_{0}, \mathrm{c}_{1}, \mathrm{c}_{2}, \mathrm{c}_{3}, \\
& \mathrm{c}_{12}, \mathrm{c}_{13}, \mathrm{c}_{23}, \mathrm{c}_{11}, \mathrm{c}_{22}, \text { and } \mathrm{c}_{33} \text { are the response surface coefficients. }
\end{aligned}
$$

3- The response surface coefficients were determined by using a CCD design type with 2 center points.

4- The prediction models, R2 and P values, were recorded.

5- The response surface and contour lines were plotted.

6- The variables resulting in maximum responses were determined by optimizing the Desirability Function.

Table 2: Variables' coding for RSM analysis

\begin{tabular}{|c|c|c|c|c|c|c|}
\hline Batch & $\begin{array}{c}\text { Coded Weight } \\
\text { Fraction }\end{array}$ & $\begin{array}{c}\text { Coded } \\
\text { Treatment }\end{array}$ & $\begin{array}{c}\text { Coded } \\
\text { length }\end{array}$ & $\begin{array}{c}\text { Flexural Strength } \\
\text { (MPa) }\end{array}$ & $\begin{array}{c}\text { Compressive } \\
\text { Strength (MPa) }\end{array}$ & $\begin{array}{c}\text { Tensile Strength } \\
\text { (MPa) }\end{array}$ \\
\hline Concrete & -1 & 0 & 0 & 5.73 & 60.75 & 4.81 \\
\hline 0.03 NCNT & -0.88 & -1 & 1 & 6.33 & 70.56 & 5.45 \\
\hline 0.08 NCNT & -0.68 & -1 & 1 & 7.16 & 71.16 & 5.65 \\
\hline 0.25 NCNT & 0 & -1 & 1 & 6.54 & 65.50 & 4.94 \\
\hline 0.5 NCNT & 1 & -1 & 1 & 6.58 & 69.23 & 4.88 \\
\hline 0.03 TCNT & -0.88 & 1 & 1 & 7.37 & 74.04 & 5.77 \\
\hline 0.08 TCNT & -0.68 & 1 & 1 & 7.15 & 67.06 & 5.52 \\
\hline 0.25 TCNT & 0 & 1 & 1 & 6.92 & 67.15 & 4.90 \\
\hline 0.5 TCNT & 1 & 1 & 1 & 5.60 & 65.15 & 4.63 \\
\hline 0.03 SCNT & -0.88 & -1 & -1 & 6.30 & 74.97 & 5.40 \\
\hline 0.08 SCNT & -0.68 & -1 & -1 & 5.93 & 67.60 & 4.74 \\
\hline 0.25 SCNT & 0 & -1 & -1 & 6.47 & 63.55 & 5.50 \\
\hline 0.5 SCNT & 1 & -1 & -1 & 6.82 & 65.80 & 4.87 \\
\hline
\end{tabular}




\section{RESULTS AND DISCUSSION}

\subsection{Strength Testing Results}

Figures 1, 2 and 3 show the flexural, compressive and tensile strength testing results, respectively. In general, the results indicated that adding CNTs to concrete can increase the flexural, compressive and tensile strengths by $29 \%, 23 \%$, and $20 \%$, respectively. Among all batches, it was shown that the batch containing 0.03 wt. \% treated CNTs could achieve the highest strength results compared with the control batch on the 90th day. The effect of CNTs' weight fraction on the strength results was noticeable. In flexural strength results (Figure 1), it was shown that long non-treated CNTs (Figure 1a) had an optimum weight fraction of $0.08 \%$, whereas short non-treated CNTs (Figure1b) had an optimum weight fraction was $0.25 \%$. For treated CNT-concrete batches (Figure 1c), the optimum weight fraction was $0.03 \mathrm{wt} . \%$. In compressive strength results (Figure 2) all types of CNTs had an optimum weight fraction of $0.03 \mathrm{wt} \%$, whereas, in tensile testing results (Figure3), the optimum weight fraction was $0.08 \%$.
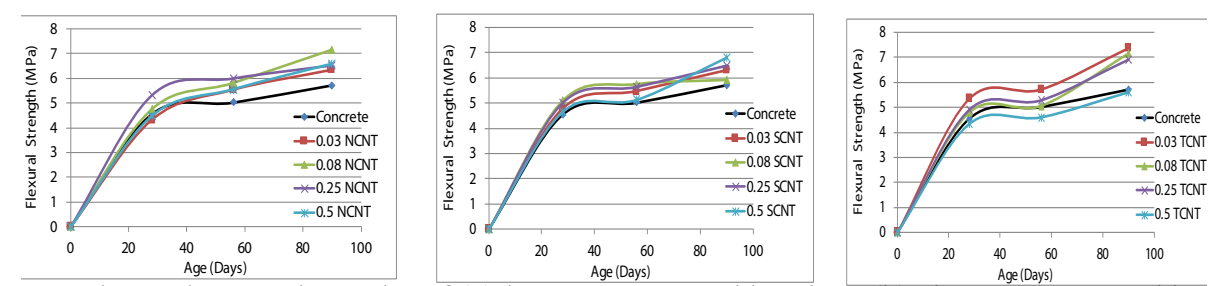

Figure 1: Flexural strength results of (a) long, non-treated batches, (b) short, non-treated batches, and (c) long, treated batches
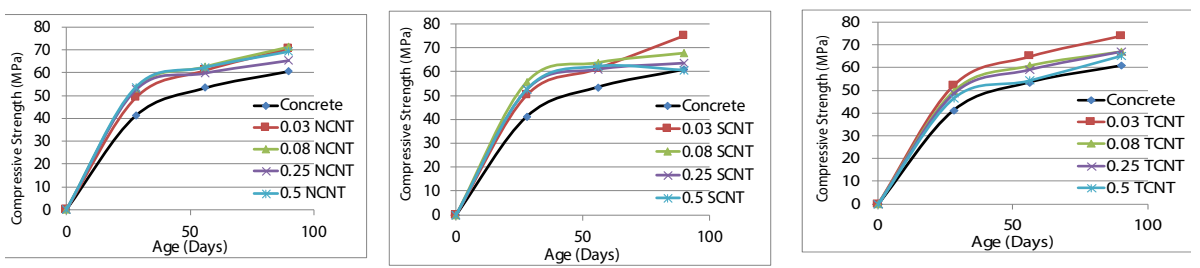

Figure 2: Compressive strength results of (a) long, non-treated batches, (b) short, nontreated batches, and (c) long, treated batches
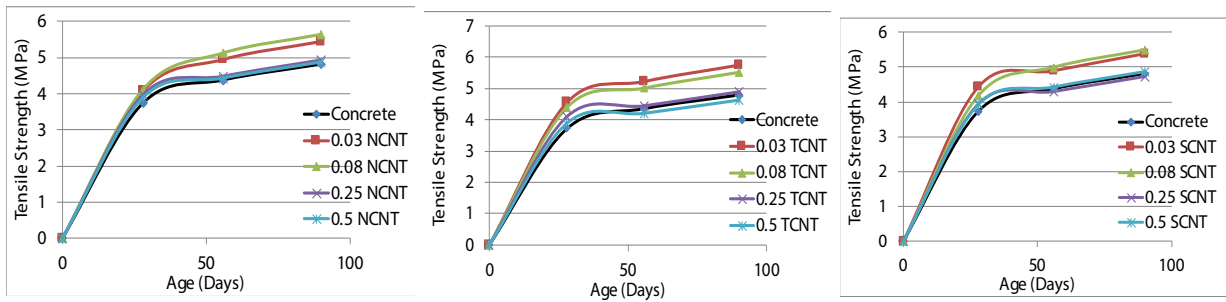

Figure 3: Tensile strength results of (a) long, non-treated batches, (b) short, non-treated batches and (c) long, treated batches

\subsection{RSM Analysis}

The RSM analysis revealed several observations about the behavior of the mechanical strength functions in terms of the weight fraction, length and treatment variables, and the 
effective amount of each variable on the function's response. Figure 4 shows the effect summary of all variables. As depicted, the analysis shows that the largest effect on the strength results was due to the weight fraction variable. The second variable, affecting the strength functions, was observed to be the length factor. Finally, the treatment factor was the least variable affecting the response results. Figure 5 shows the response surface plot of flexural strength against the weight fraction, treatment and length variables. The response chart shows peaks at the mid boundary, where the weight fraction is about 0.25 wt.\%. The response surfaces also illustrate that higher results can be obtained for long treated CNTs.

The flexural strength prediction equation was determined as the follows:

$\mathrm{FS}=7.10+0.136 \mathrm{x}_{1}-0.044 \mathrm{x}_{2}+0.0023 \mathrm{x}_{3}-0.190 \mathrm{x}_{1} \mathrm{x}_{2}-0.295 \mathrm{x}_{1} \mathrm{x}_{3}-0.0841 \mathrm{x}_{2} \mathrm{x}_{3}-0.956 \mathrm{x}_{1}^{2}$ $-0.1063 \mathrm{x}_{2}^{2}+0.29 \mathrm{x}_{3}^{2}$

where, FS: Flexural Strength, $\mathrm{x}_{1}$ : Weight Fraction, $\mathrm{x}_{2}$ : Treatment, and $\mathrm{x}_{3}$ : Length The $\mathrm{R}^{2}$ and $\mathrm{P}$ values of the flexural strength-predicted model were determined as 0.92 and 0.1571 , respectively.

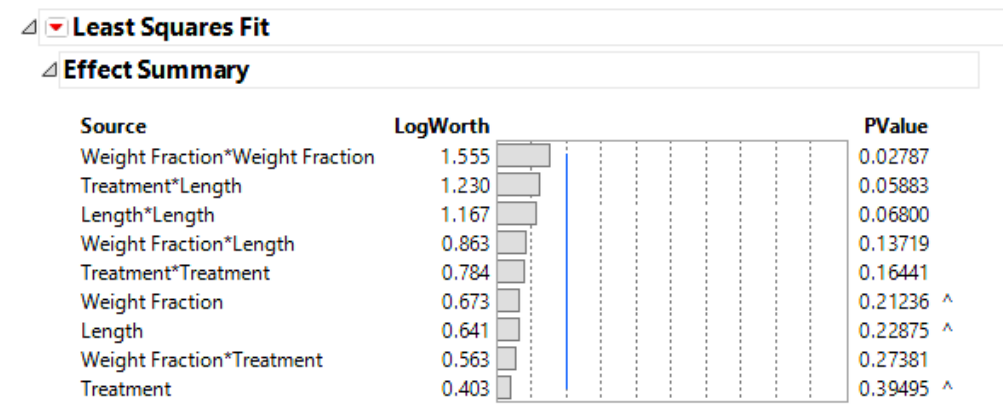

Figure 4: Effect summary of the study variables on the mechanical properties' functions
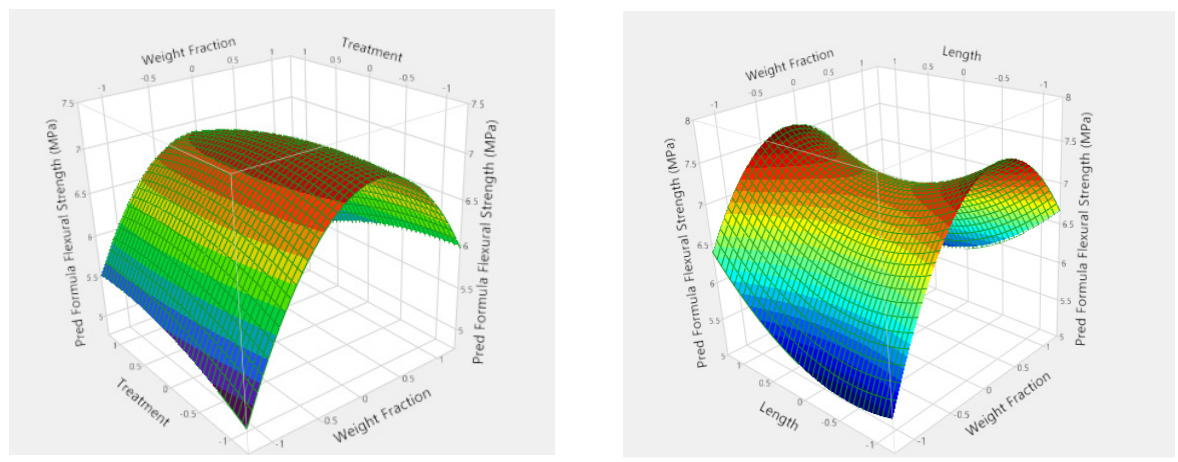

Figure 5: RSM models of flexural strength against (a) weight fraction and treatment, and (b) weight fraction and length

Figure 6 shows the response surface plot of compressive strength against the weight fraction, treatment and length variables. Similar to the response of the flexural strength function, the response chart shows peaks at the mid boundary, where the weight fraction is about $0.25 \mathrm{wt} . \%$. The response surfaces also illustrate that higher compressive strength results can be obtained for long treated CNTs. 

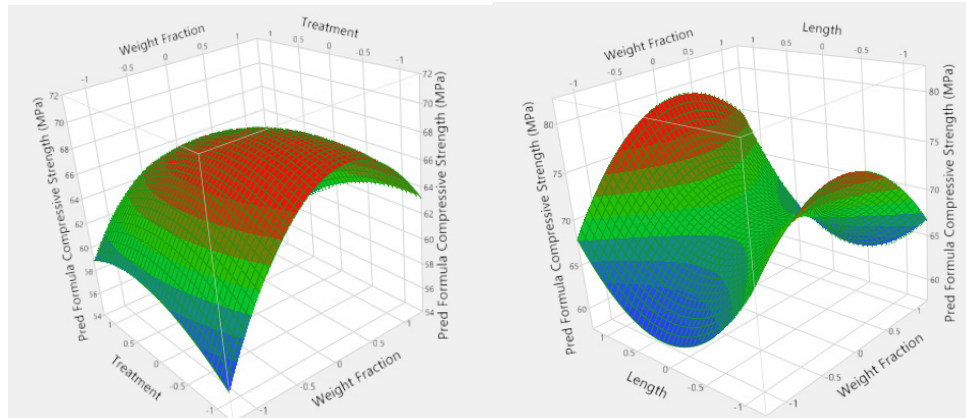

Figure 6: RSM models of compressive strength against (a) weight fraction and treatment and (b) weight fraction and length

The compressive strength prediction equation was determined as the following: $\mathrm{CS}=68.56+0.73 \mathrm{x}_{1}-1.02 \mathrm{x}_{2}+1.23 \mathrm{x}_{3}-1.615 \mathrm{x}_{1} \mathrm{x}_{2}+1.571 \mathrm{x}_{1} \mathrm{x}_{3}-1.579 \mathrm{x}_{2} \mathrm{x}_{3}-4.787 \mathrm{x}_{1}^{2}-$ $1.482 \mathrm{x}_{2}^{2}+5.543 \mathrm{x} 32$

where,

CS: Compressive Strength, $\mathrm{x}_{1}$ : Weight Fraction, $\mathrm{x}_{2}$ : Treatment, and $\mathrm{x}_{3}$ : Length

The $\mathrm{R}^{2}$ and $\mathrm{P}$ values of the compressive strength-predicted model were determined as 0.89 and 0.2155 , respectively.

Figure 7 shows the response surface plot of tensile strength against the weight fraction, treatment and length variables. The response chart shows peaks at the mid boundary, where the weight fraction is about $0.31 \mathrm{wt} . \%$. The response surfaces also illustrate that higher tensile strength results can be obtained for long treated CNTs.

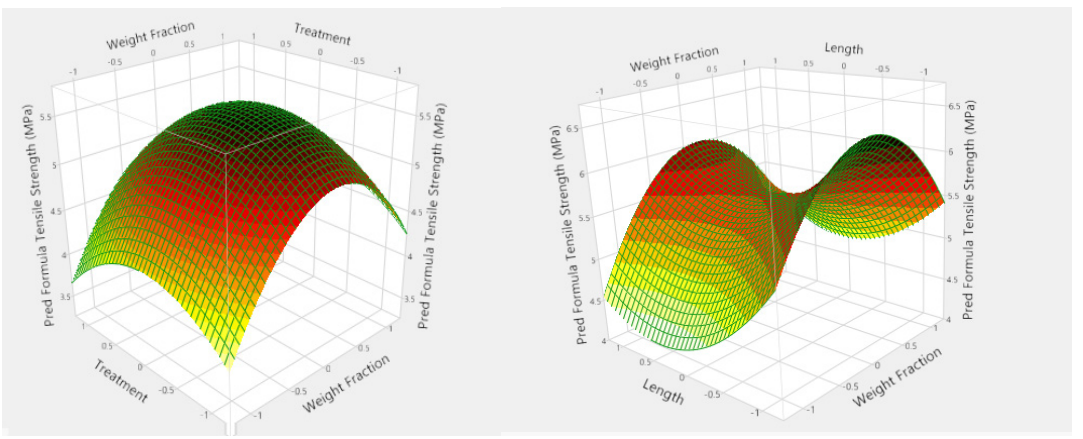

Figure 7: RSM models of tensile strength against (a) weight fraction and treatment and (b) weight fraction and length

The tensile strength prediction equation was determined as the following: $\mathrm{TS}=5.57+0.165 \mathrm{x}_{1}-0.071 \mathrm{x}_{2}-0.179 \mathrm{x}_{3}-0.0073 \mathrm{x}_{1} \mathrm{x}_{2}+0.110 \mathrm{x}_{1} \mathrm{x}_{3}-0.362 \mathrm{x}_{2} \mathrm{x}_{3}-0.683 \mathrm{x}_{1}^{2}$ $-0.363 \mathrm{x}_{2}^{2}+0.41 \mathrm{x}_{3}^{2}$ where,

TS: Tensile Strength, $x 1$ : Weight Fraction, $x 2$ : Treatment, and x3: Length

The R2 and P value of the tensile strength-predicted model were determined as 0.89 and 0.2356 , respectively. 
Figure 8 shows the maximized Desirability Strengths Functions behavior in-terms of the weight fraction, treatment and length variables. By maximizing the desirability function, it was shown that the maximum behavior could occur at a weight fraction of 0.3 wt.\% (i.e. coded value $=0.14$ ) using long non-treated CNTs. The maximum predicted flexural, compressive and tensile strengths will be $7.41,76.91$ and $5.93 \mathrm{MPa}$, respectively. Compared to control concrete, these values indicate $23 \%, 12 \%$ and $25 \%$ increase in flexural, compressive and tensile strengths, respectively.

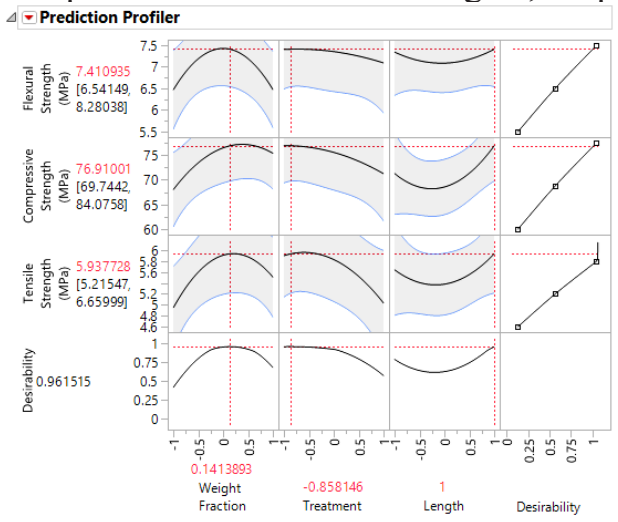

Figure 8: Maximized desirability functions

Figure 9 shows the combined contour profiles of the weight fraction and treatment variables versus the flexural, compressive and tensile strengths for long treated CNTs. The shaded areas show all flexural, compressive and tensile strengths falling below lower strengths limits of 7,70 and 4.9 MPa, respectively. These maps illustrate the importance of using, a weight fraction variable of 0.2 wt.\% (i.e. -0.0731 coded) to maximize the flexural strength while maintaining the compressive and tensile above the lower limits. Figure 10 shows the combined contour profiles of the weight fraction and treatment variables versus the flexural, compressive and tensile strength when short, non-treated filaments were used. The shaded areas shown include all flexural, compressive and tensile strengths falling below lower strengths limits of 7.2, 70 and $5.5 \mathrm{MPa}$, respectively. It was observed that in order to obtain the maximum flexural strength value with the compressive and tensile above the lower limits, we need to maintain a weight fraction variable of 0.25 wt. $\%$ short CNTs (i.e. 0 coded). 


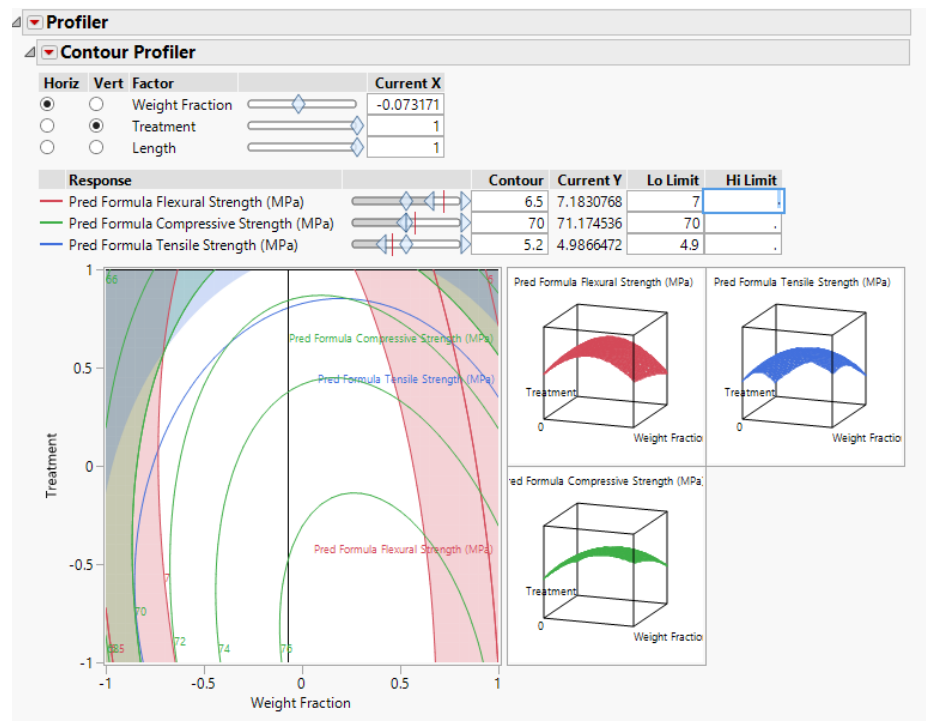

Figure 9: Contour maps of the maximum desirable flexural strength for long treated CNT-concrete batch

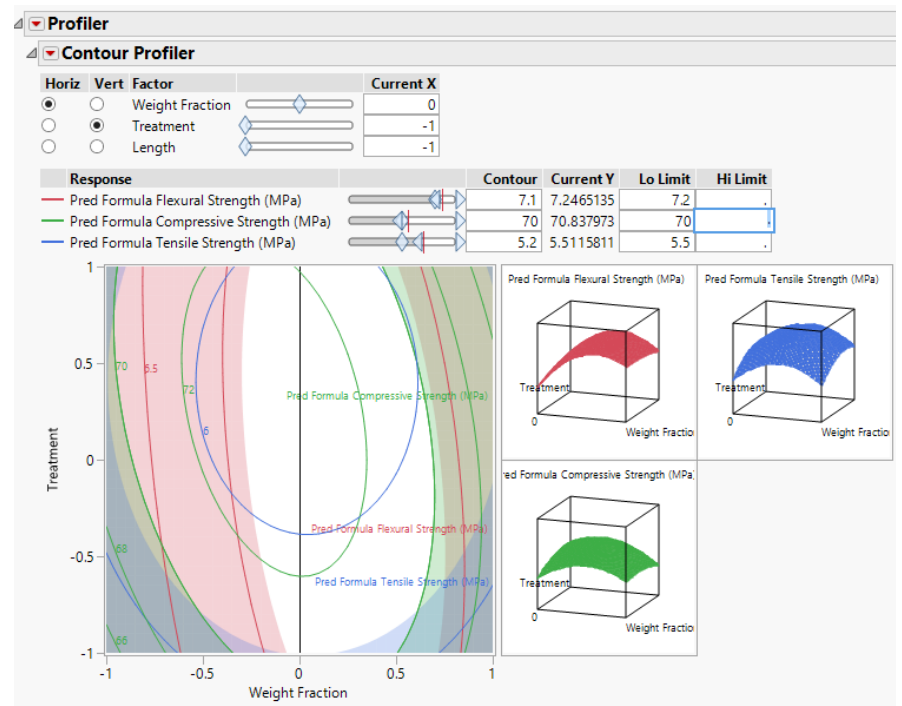

Figure 10: Contour maps of the maximum desirable flexural strength for short-nontreated CNT-concrete batch

\section{CONCLUSION}

In this research, the effect of multi-walled carbon nanotubes' (MWCNTs) content, length and treatment parameters on the mechanical properties of concrete composites were studied. Several conclusions could be reached as follows:

1. Using CNTs in concrete batches will increase the flexural, compressive and tensile strengths by $29 \%, 23 \%$ and $20 \%$, respectively.

2. The batch of $0.03 \%$ treated CNTs appeared to be the optimum concrete batch among all tested mixes, in terms of strength gain and cost savings. 
3. RSM techniques proposed empirical formulas to determine the flexural, compressive and tensile strengths of CNTs-Concrete composites.

4. The RSM analysis results showed that the maximum strength properties could be obtained at a weight fraction of $0.3 \mathrm{wt} . \%$ with long non-treated CNTs. By applying these variables (i.e. $0.3 \mathrm{wt} . \%$, long and non-treated CNTs), the model predicts increases of $23 \%, 12 \%$ and $25 \%$ in flexural, compressive and tensile strengths, respectively, compared to plain concrete.

5. The RSM analysis also showed that the maximum flexural strength properties could be obtained in long, non-treated CNTs and short, non-treated CNTs when weight fractions of $0.2 \%$ and $0.25 \%$ were used, respectively.

\section{REFERENCES}

AbuTaqa, A., Al-Rub, R., Senouci, A., Al-Nuaimi, N. \& Bani-Hani, K. A. (2015). The Effect of Fiber Geometry and Interfacial Properties on the Elastic Properties of Cementitious Nanocomposite Material, J Nanomater.

Al-Dahawi, A., Öztürk, O., Emami, F., Yıldırım, G. \& Sahmaran, M. (2016). Effect of mixing methods on the electrical properties of cementitious composites incorporating different carbon-based materials. Construction and Building Materials, 104, 160-168.

ASTM C39/C39M - 17 (2017). Standard Test Method for Compressive Strength of Cylindrical Concrete Specimens, West Conshohocken, PA, 2017, 8 pp.

ASTM C78/C78M - 16 (2016). Standard Test Method for Flexural Strength of Concrete (Using Simple Beam with Third-Point Loading), West Conshohocken, PA, 2016, 4 pp.

ASTM C496/C496M - 11 (2011). Standard Test Method for Splitting Tensile Strength of Cylindrical Concrete Specimens, West Conshohocken, PA, PA, 2011, 5 pp.

Chuah, S., Pan, Z., Sanjayan, J., Wang, C. \& Duan, W. (2014). Nano reinforced cement and concrete composites and new perspective from graphene oxide. Construction and Building Materials, 73, 113-124.

Hawreen, A., Bogas, J. A. \& Dias, A. P. S. (2018). On the mechanical and shrinkage behavior of cement mortars reinforced with carbon nanotubes. Construction and Building Materials, 168: 459-470.

Hu, Y., Luo, D., Li, P., Li, Q. \& Sun, G. (2014). Fracture toughness enhancement of cement paste with multi-walled carbon nanotubes. Construction and Building Materials, 70, 332-338.

Kim, H. K., Nam, I. W. \& Lee, H. K. (2014). Enhanced effect of carbon nanotube on mechanical and electrical properties of cement composites by incorporation of silica fume. Composite Structures, 107: 60-69.

Krämer, C., Schauerte, M., Müller, T., Gebhard, S. \& Trettin, R. (2017). Application of reinforced three-phase-foams in UHPC foam concrete. Construction and Building Materials, Volume 131, 30 January 2017, Pages 746-757.

Luo, J., Hou, D., Li, Q., Wu, C. \& Zhang, C. (2017). Comprehensive performances of carbon nanotube reinforced foam concrete with tetraethyl orthosilicate impregnation. Construction and Building Materials, Volume 131, 30 January 2017, 512-516.

Mohsen, M., Taha, R., Abu Taqa, A. \& Shaat, A. (2017). Optimum carbon nanotubes' content for improving flexural and compressive strength of cement paste. Constr. Build. Mater, 150 (2017) 395-403. 
Paula, J. N. D., Calixto, J. M., Ladeira, L. O., Ludvig, P., Souza, T. C. C., Rocha, J. M. \& Melo, A. A. V. D. (2014). Mechanical and rheological behavior of oil-well cement slurries produced with clinker containing carbon nanotubes. Journal of Petroleum Science and Engineering, 122 (274-279).

Siddique, R. \& Mehta, A. (2014). Effect of carbon nanotubes on properties of cement mortars. Construction and Building Materials. Construction and Building Materials, 50, 116-129.

Song, X., Shang, S., Chen, D. \& Gu, X. (2017). Multi-walled carbon nanotube reinforced mortaraggregate interfacial properties. Construction \& Building Materials, 133:57-64.

Wang, B., Han, Y. \& Liu, S. (2013). Effect of highly dispersed carbon nanotubes on the flexural toughness of cement-based composites. Construction and Building Materials, 46, 8-12. 